\title{
Cigarette smoking and KRAS oncogene mutations in sporadic colorectal cancer: results from the Netherlands Cohort Study
}

Citation for published version (APA):

Weijenberg, M. P., Aardening, P. W., de Kok, T. M., de Goeij, A. F., \& van den Brandt, P. A. (2008). Cigarette smoking and KRAS oncogene mutations in sporadic colorectal cancer: results from the Netherlands Cohort Study. Mutation Research-Genetic Toxicology and Environmental Mutagenesis, 652(1), 54-64. https://doi.org/10.1016/j.mrgentox.2007.12.008

Document status and date:

Published: 01/01/2008

DOI:

10.1016/j.mrgentox.2007.12.008

Document Version:

Publisher's PDF, also known as Version of record

\section{Document license:}

Taverne

Please check the document version of this publication:

- A submitted manuscript is the version of the article upon submission and before peer-review. There can be important differences between the submitted version and the official published version of record.

People interested in the research are advised to contact the author for the final version of the publication, or visit the DOI to the publisher's website.

- The final author version and the galley proof are versions of the publication after peer review.

- The final published version features the final layout of the paper including the volume, issue and page numbers.

Link to publication

\footnotetext{
General rights rights.

- You may freely distribute the URL identifying the publication in the public portal. please follow below link for the End User Agreement:

www.umlib.nl/taverne-license

Take down policy

If you believe that this document breaches copyright please contact us at:

repository@maastrichtuniversity.nl

providing details and we will investigate your claim.
}

Copyright and moral rights for the publications made accessible in the public portal are retained by the authors and/or other copyright owners and it is a condition of accessing publications that users recognise and abide by the legal requirements associated with these

- Users may download and print one copy of any publication from the public portal for the purpose of private study or research.

- You may not further distribute the material or use it for any profit-making activity or commercial gain

If the publication is distributed under the terms of Article $25 \mathrm{fa}$ of the Dutch Copyright Act, indicated by the "Taverne" license above, 


\title{
Cigarette smoking and $K R A S$ oncogene mutations in sporadic colorectal cancer: Results from the Netherlands Cohort Study
}

\author{
M.P. Weijenberg ${ }^{\text {a,* }}$, P.W.M. Aardening a , T.M. de Kok ${ }^{\text {, }}$, \\ A.F.P.M. de Goeij ${ }^{\mathrm{a}}$, P.A. van den Brandt ${ }^{\mathrm{a}}$ \\ a GROW-School for Oncology and Developmental Biology, University Maastricht, Department of Epidemiology, \\ Maastricht University, Maastricht, The Netherlands \\ ${ }^{\mathrm{b}}$ Nutrition and Toxicology Research Institute Maastricht (NUTRIM), Department of Health Risk Analysis and Toxicology, \\ Maastricht University, Maastricht, The Netherlands
}

Received 6 March 2007; received in revised form 16 November 2007; accepted 10 December 2007

Available online 11 January 2008

\begin{abstract}
Since a KRAS oncogene mutation is an early event in colorectal cancer development and cigarette smoking is thought to have an effect on early stages of colorectal tumorigenesis, smoking, especially long-term smoking, may be associated with the risk for colorectal cancer with $K R A S$ oncogene mutations.

In the Netherlands Cohort Study on diet and cancer ( $n=120,852$ men and women), using a case-cohort design, adjusted incidence rate ratios (RR) and 95\% confidence intervals (CI) were computed for colorectal tumors with wild-type and with mutated KRAS gene, and with specific $\mathrm{G}: \mathrm{C} \rightarrow \mathrm{T}: \mathrm{A}$ or $\mathrm{G}: \mathrm{C} \rightarrow \mathrm{A}: \mathrm{T}$ point mutations in $K R A S$, according to cigarette smoking status, frequency, duration, pack years, age at first exposure, years since cessation, inhalation and filter usage. After 7.3 years and excluding the first 2.3 years, 648 cases and 4083 sub-cohort members were included in the analyses.

Ex-smokers, but not current smokers, were at increased risk for colorectal cancer with wild-type KRAS gene tumors when compared with never smokers, albeit not statistically significant (RR 1.26, 95\% CI 0.96-1.66). This was not observed for KRAS mutated tumors when comparing ex-smokers with never smokers (RR 1.15, 95\% CI 0.79-1.66). The highest category of smoking frequency ( $>20$ cigarettes/day) and inhalation of smoke were associated with an increased risk for colorectal cancer with wild-type KRAS gene tumors, though not statistically significant, when compared with never smoking (frequency: RR $1.24,95 \%$ CI $0.90-1.71$ and inhalation: RR $1.25,95 \%$ CI 0.94-1.67). These associations were strongest in men (ex-smokers: RR 1.79, 95\% CI 1.00-3.20; frequency: RR 1.91, 95\% CI 1.03-3.52; inhalation: RR 1.69, 95\% CI 0.94-3.04). No associations were observed between any of the smoking characteristics and the risk for colorectal cancer with mutated $K R A S$ gene tumors, nor where there any clear associations with tumors with specific $\mathrm{G}: \mathrm{C} \rightarrow \mathrm{A}: \mathrm{T}$ transitions or $\mathrm{G}: \mathrm{C} \rightarrow \mathrm{T}: \mathrm{A}$ transversions.

These results suggest that, in contrast to the hypothesis, smoking does not increase the risk for colorectal tumors with a mutated KRAS gene. Some smoking characteristics, i.e. being an ex-smoker, frequency and inhalation, may be associated with risk for colorectal cancer characterized by the wild-type $K R A S$ gene, especially in men.
\end{abstract}

(C) 2008 Elsevier B.V. All rights reserved.

Keywords: Smoking; Colorectal cancer; Prospective study; Netherlands Cohort Study; KRAS oncogene; Molecular epidemiology

\section{Introduction}

With the burning of tobacco products, numerous genotoxic compounds are formed, including carcinogenic polycyclic aromatic hydrocarbons, heterocyclic amines and aromatic amines

\footnotetext{
* Corresponding author. Tel.: +31 43 3882358; fax: +31 433884128 .

E-mail address: MP.Weijenberg@epid.unimaas.nl (M.P. Weijenberg).
}

[1]. Smoking is associated with a higher risk for cancer in various tissues, including lung, oral cavity, pharynx, larynx, pancreas, urinary bladder, renal pelvis, nasal cavities and paranasal sinuses, nasopharynx, stomach, liver, kidney, cervix and esophagus [1,2]. Although associations between smoking and colorectal carcinomas have been inconsistent, long-term, heavy smoking has been associated with a two- to threefold increased risk for colorectal adenomas [3]. In addition, current smoking has been observed to be more strongly associated with 
hyperplastic polyps than with adenomatous polyps [4]. As most colorectal carcinomas arise from pre-existing benign neoplasms, the association between smoking and colorectal adenomas led to the assumption that smoking may be involved in early tumorigenesis. Development of colorectal cancer is thought to be a multi-step process which involves the accumulation of aberrations in a number of genes [5]. The Fearon and Vogelstein model assumes the involvement of the KRAS (v-Ki-ras2 Kirsten rat sarcoma viral oncogene homolog) oncogene in the transition from intermediate adenomas to carcinomas in sporadic colorectal cancer [6]. Somatic mutations can cause oncogenic activation of KRAS. This genetic alteration occurs in adenomas as well as in carcinomas in colon and rectal cancer. Approximately $90 \%$ of the activating mutations are found in codons 12 and 13 . The predominant mutations are $\mathrm{G}: \mathrm{C} \rightarrow \mathrm{A}: \mathrm{T}$ transitions and $\mathrm{G}: \mathrm{C} \rightarrow \mathrm{T}: \mathrm{A}$ transversions [7-10]. Because smoking is thought to be involved in the early stages of colorectal tumorigenesis, smoking may be associated with mutations in the KRAS oncogene. Results from rodent studies support this hypothesis: benzo(a)pyrene was found to induce $\mathrm{G}: \mathrm{C} \rightarrow \mathrm{T}: \mathrm{A}$ transversions and $N$-nitrosamines were found to induce $\mathrm{G}: \mathrm{C} \rightarrow \mathrm{A}: \mathrm{T}$ transitions in $R A S$ oncogenes [11]. Both chemicals are present in tobacco smoke.

The aim of the present study is to investigate the relationship between cigarette smoking and risk for overall colorectal cancer and risk for colorectal cancer with wild-type or mutated $K R A S$ oncogene tumors in a prospective cohort study. We studied associations between cigarette smoking and the risk for colon, rectosigmoid and rectal cancer, with wild-type or mutated $K R A S$ oncogene tumors within the Netherlands Cohort Study on diet and cancer (NLCS). Additionally, we assessed associations between cigarette smoking and colorectal cancer with a specific $\mathrm{G}: \mathrm{C} \rightarrow \mathrm{T}: \mathrm{A}$ or $\mathrm{G}: \mathrm{C} \rightarrow \mathrm{A}: \mathrm{T}$ point mutation.

\section{Materials and methods}

The prospective Netherlands Cohort Study (NCLS) on diet and cancer was started in 1986. The total cohort includes 120,852 persons aged between 55 and 69 years old at baseline, of which 58,279 are men and 62,573 are women. The study subjects originated from 204 Dutch municipal population registries. In order to be included, municipalities had to satisfy two criteria: (a) availability of a computerized population registry and (b) sufficient cancer follow-up coverage. A self-administered questionnaire on diet, other risk factors for cancer and potential confounders was completed at baseline [12]. The entire cohort is being monitored for cancer occurrence by annual record linkage to the Netherlands Cancer Registry (NCR) and Pathologisch Anatomisch Landelijk Geautomatiseerd Archief (PALGA), a nationwide database of histo- and cytopathology reports [13]. Combining the NCR and PALGA resulted in almost $100 \%$ coverage of the municipalities included in the NLCS.

The present analyses were carried out over the 7.3-year period of followup since September 1986. Accumulation of person-time in the cohort has been estimated through biennial vital status follow-up. A sample of 5000 men and women were randomly selected from the cohort after baseline exposure measurement to estimate the number of personyears for the entire cohort, whereas cases are enumerated for the entire cohort $[14,15]$. The sub-cohort was followed-up biennially to assess information on vital status and migration in order to calculate accumulated person-time in the cohort. Excluded from the sub-cohort were cases with prevalent cancer other than non-melanoma skin cancer. Because of incomplete nationwide coverage of PALGA alone in some of the municipalities included in the NLCS in that period and because of possible pre-clinical disease affecting exposure status, the first 2.3 years of follow-up were also excluded. In the period from 1989 till 1994, 925 incident cases with histologically confirmed colorectal cancer were observed, of which 815 could be linked to a PALGA report of the lesion. With a PALGA report, tumor tissue form eligible colorectal cancer patients could be located and identified in Dutch pathology laboratories. Collection of tumor tissue specimens started in August 1999 and was completed in December 2001. The loss to follow-up of tissue samples of cases amounted to $5 \%$. Colorectal cancer was classified according to site as follows: colon, i.e. cecum through sigmoid colon (ICD-O-1 codes: 153.0, 153.1, 153.2, 153.3, 153.4, 153.5, 153.6, 153.7, 153.8, 153.9), rectosigmoid (ICD-O-1 code 154.0) and rectum (ICD-O-1 code 154.1).

After approval by the Medical Ethical Committees (MEC) of Maastricht University, PALGA and the NCR, tumor material was collected. All pathology laboratories in the Netherlands agreed to make relevant tissue samples available for this study. The 815 tissue samples were distributed among 54 pathology laboratories throughout the Netherlands. Only 44 (5\%) tumor tissue samples could not be traced. Finally, 771 (95\%) of the available tissue samples were retrieved and $734(90 \%)$ of these contained sufficient tumor material, making molecular analyses possible [10]. DNA isolation is described elsewhere [10]. Briefly, sections $(5 \mu \mathrm{m})$ were cut from paraffin-embedded tumor tissue blocks and stained with haematoxylin and eosin (H\&E) for histopathological examination. Five $20-\mu \mathrm{m}$ sections of tumor tissue were used for DNA extraction. Tumor tissue was macrodissected from the normal colonic epithelium using the HE section as a reference. Proteinase K stock solution $(20 \mathrm{mg} / \mathrm{ml}$, obtained form Qiagen, St. Louis, MO, USA) and the Puregene ${ }^{\circledR}$ DNA Isolation Kit (Gentra Systems, Minneapolis, MN, USA) were used to extract genomic DNA from the macrodissected tumor tissue. The DNA concentration and purity were established spectrophotometrically at 260 and $280 \mathrm{~nm}$ [10].

Mutation analysis of the exon 1 fragment of the KRAS oncogene, spanning codons 8-29, was performed on archival colorectal adenocarcinoma specimens of 734 patients, using macrodissection, nested polymerase chain reaction (PCR) and direct sequencing of purified fragments. The detection limit was 5\% mutated DNA. Duplicate experiments revealed a good reproducibility (88\%) [10].

Exposure to tobacco smoke of all cancer cases and sub-cohort members was derived from the questionnaire. Exposure to smoke from cigarettes was characterized by eight smoking variables: smoking status (never, former and current), frequency, duration, pack years of smoking, age at first exposure, years since cessation, inhalation and filter usage. The never-smoker category was considered to be the reference for all variables. For categorical analyses, frequency was divided in the categories: less than 10,10-20 and more than 20 cigarettes smoked per day. Duration of smoking was categorized as: less than 20, 20-40 and more than 40 years of cigarette smoking. The variable pack-years was divided in the categories: less than 9, 10-30 and more than 30 pack-years of cigarette smoking. Age at first exposure was categorized as: younger than 17, 17-21 and older than 21 years of age. Years since cessation was divided in the categories: less than $10,10-30$ and more than 30 years since cessation. Inhalation was categorized as yes or no. Filter usage was divided in filter- and non-filter-tipped cigarette use.

The dietary section of the questionnaire is a 150 -item semi-quantative foodfrequency questionnaire, which concentrated on habitual consumption of food and beverages during the year preceding the start of the study as well on lifestyle factors. Questionnaires were key-entered twice and automatically coded by the data-entry program. Data were checked for completeness, consistency, range and other response errors and corrected by means of an SPSS computer program. Questionnaires were excluded when incomplete or inconsistent. Criteria used for this selection were (a) 60 or more questionnaire items left blank or consumption of 35 or more food items less than once a month and/or (b) one or more item blocks (groups of items, for example beverages) left blank. Additional details are given elsewhere [16]

The distribution of the smoking variables as well as the distributions of the variables sex, family history of colorectal cancer (yes/no) and physical activity in leisure time $(<30,30-60,60-90,>90 \mathrm{~min} /$ day $)$, and the mean value of age at baseline (years), intake of energy (kJ/day), fat (g/day), dietary fiber (g/day), alcohol (g/day), coffee ( $\mathrm{ml} /$ day), calcium ( $\mathrm{mg} /$ day), vitamin A ( $\mathrm{mg} /$ day), vitamin C (mg/day), vitamin E (mg/day), $\beta$-carotene ( $\mu \mathrm{g} /$ day) and body mass index (BMI) $\left(\mathrm{kg} / \mathrm{m}^{2}\right)$, were evaluated for sub-cohort members and colorectal cancer patients with wild-type or mutated KRAS gene tumors. Differences 
in the mean values of the continuous variables between patients with wildtype or mutated KRAS gene tumors were tested with the Student's $t$-test or Mann-Whitney $U$ test if the variables were not normally distributed. We used the $\chi^{2}$ test to test for differences in the distributions of the categorical variables between patients with wild-type or mutated KRAS gene tumors. The analyses were conducted separately for colorectal cancer overall, for colorectal cancer cases with wild-type or mutated KRAS gene tumors, and for tumors with a specific $\mathrm{C}: \mathrm{G} \rightarrow \mathrm{T}: \mathrm{A}$ or $\mathrm{G}: \mathrm{C} \rightarrow \mathrm{T}: \mathrm{A}$ point mutation. Similar analyses were conducted for different sub-sites of the colorectal tract, i.e. proximal and distal colon cancer, rectosigmoid cancer and rectal cancer and the different molecular subgroups thereof. No differences were observed between any of the sub-sites, therefore only data of the analyses for colorectal cancer overall are presented.

Incident rate ratios (RR) and corresponding 95\% confidence intervals (CI) for colorectal cancer cases with wild-type or mutated KRAS gene tumors were estimated according to cigarette smoking status (never, ex, current), smoking frequency (cigarettes/day), smoking duration (years), pack years, age when starting smoking (years), time since smoking cessation (years) and corresponding continuous variables compared with lifelong non-smokers using Cox proportional hazards regression models with the STATA statistical software package (intercooled STATA, Version 8.2). Standard errors were estimated using the robust Huber-White sandwich estimator to account for additional variance introduced by sampling from the cohort [17]. The proportional hazard assumption was tested using the scaled Schoenfeld residuals [18]. Tests for dose-response trends over the different categories of smoking variables were estimated by fitting the ordinal exposure variables as continuous terms and evaluated using the Wald test. Life-long non-smokers were excluded for estimation of the $p$-value for trend over the categories of age when started smoking and years since smoking cessation.

All potential confounders were separately tested in the models for overall colorectal cancer with wild-type or mutated KRAS gene tumors. Variables that showed $a \geq 10 \%$ influence on the RR for cancer or were found to contribute ( $p$ value $<0.10$ ) to any of the multivariate models (age at baseline, sex), by means of the Wald test were included in the multivariate analyses. Variables that were identified as confounders in the literature were also considered confounders. Finally age, sex, family history of colorectal cancer, BMI, alcohol and coffee consumption were considered as confounders and analyses were adjusted for these variables. Among all members and cases, questions on whether subjects drank coffee were left blank by 10 persons. They were considered to be nondrinkers. Forty-four subjects reported drinking coffee, but did not report how much. They were assumed to drink the mean amount of coffee consumed by the drinkers in the sub-cohort $(534 \mathrm{ml} /$ day). For 143 sub-cohort members and 24 colorectal cancer cases data on BMI were missing. Data on alcohol were missing for 117 sub-cohort members and 11 colorectal cancer cases. These members and cases were excluded from the analyses. The Pearson correlation coefficient between smoking duration and smoking frequency was strong $(r=0.80)$. Therefore, the variable smoking duration is not adjusted for frequency, and the variable smoking frequency is not adjusted for duration. Eventually, 648 colorectal cancer patients ( 367 men, 281 women) and 4083 sub-cohort members (2031 men, 2052 women) were included in the analyses.

Possible interaction by sex, alcohol, vitamin A, vitamin C, vitamin E and $\beta$-carotene was investigated by entering an interaction term in the model and assessing the significance of this term using the Wald test. No interactions were observed for any of the mentioned variables, and therefore results are shown combined for men and women and for the other variables. Nevertheless, since men and women differ considerably with respect to smoking habits, analyses for the risk of KRAS wild-type and mutated colorectal tumors according to the main smoking variables (smoking status, frequency and duration) are also presented separately for men and women. Finally, since ex-smokers, compared with never smokers, appeared to be at a higher risk for cancer in some subgroup analyses and because current smokers were never at increased risk, analyses were also conducted separately for ex- and current smokers. Specifically, analyses of the risk for KRAS wild-type and mutated colorectal tumors with frequency and duration of smoking are presented separately for the ex-smokers and current smokers, using never smokers as a reference. These extra analyses are not presented for cancers with specific mutations, since in each of these analyses at least one of the cells contained less than 10 cases, which hampers a sound interpretation of the results.
All $p$-values reported are for a two-sided test; $p$-values of less than 0.05 were considered to be statistically significant.

\section{Results}

Smoking habits and other baseline characteristics for subcohort members and colon, rectosigmoid and rectal cancer cases with wild-type or mutated KRAS gene tumors are shown in Table 1. Colon, rectosigmoid and rectal cancer cases were more often men, were older and more frequently reported a family history of colorectal cancer compared with the sub-cohort. Colon cancer cases with mutated KRAS tumors were significantly older, had higher daily intakes of vitamin $\mathrm{E}$ and more frequently reported smoking both cigarettes and cigars than colon cancer cases with a wild-type KRAS tumor, but the latter finding is based on few cases (i.e. 17 and 18, respectively). There were no statistically significant differences between colon cancer cases with a wild-type $K R A S$ tumor and a mutated KRAS tumor in all other factors presented in Table 1 . No statistically significant differences were observed between rectosigmoid cancer cases with wild-type KRAS tumors and mutated KRAS tumors or between rectal cancer cases with wild-type $K R A S$ tumors and mutated $K R A S$ tumors for smoking and other factors. Since smoking of cigars and pipe was rare $(<1 \%)$ further data will only be presented for cigarette smoking.

Multivariate-adjusted RR for colorectal cancer overall, colorectal cancer with wild-type KRAS tumors and colorectal cancer with mutated $K R A S$ tumors according to the smoking variables are presented in Table 2 . The presented multivariate RRs are based on 648 colorectal cancer patients and 4083 sub-cohort members. Ex-smokers were at increased risk for overall colorectal cancer compared with never smokers (RR 1.22 ; $95 \%$ CI $0.97-1.53$ ), but the association was not statistically significant. Current smokers were not at increased risk for overall colorectal cancer in comparison with never smokers (RR $0.81 ; 95 \%$ CI 0.61-1.05). There were no significant associations between smoking frequency, smoking duration, pack years, age at first exposure, years since cessation, inhalation or filter usage and the risk for colorectal cancer. Associations between ex-smokers, smoking frequency, inhalation and the risk for colorectal cancer with a wild-type KRAS gene appeared to be stronger than for the risk for colorectal cancer with a mutated $K R A S$ gene, where these associations were absent. Ex-smokers were at increased risk for developing colorectal cancer with a wild-type KRAS gene when compared with never smokers (RR 1.26; 95\% CI 0.96-1.66), although the association was not statistically significant. The highest category of smoking frequency ( $>20$ cigarettes/day) and inhalation were associated with an increased risk for colorectal cancer with a wild-type KRAS gene, although not statistically significant (frequency: RR 1.24; 95\% CI 0.90-1.71 and inhalation: RR 1.25; 95\% CI 0.94-1.67). No associations were observed between the remaining smoking variables, i.e. smoking duration, pack years, age at first exposure, years since cessation, filter usage and the risk for colorectal cancer with wild-type KRAS gene tumors. Regarding mutated $K R A S$ tumors, none of the smoking variables were associated with risk for this type of colorectal cancer. 
Table 1

Baseline characteristics of subcohort members, colon, rectosigmoid and rectal cancer cases with wild-type or mutated KRAS gene tumors from the NLCS after 7.3 years of follow-up ${ }^{\text {a }}$

\begin{tabular}{|c|c|c|c|c|c|c|c|c|c|c|}
\hline & \multirow[t]{2}{*}{ Subcohort } & \multicolumn{3}{|l|}{ Colon cancer } & \multicolumn{3}{|c|}{ Rectosigmoid cancer } & \multicolumn{3}{|l|}{ Rectal cancer } \\
\hline & & Wild-type $K R A S$ & Mutated $K R A S$ & $p$-Value ${ }^{\mathrm{b}}$ & Wild-type $K R A S$ & Mutated $K R A S$ & $p$-Value ${ }^{b}$ & Wild-type $K R A S$ & Mutated $K R A S$ & $p$-Value ${ }^{\mathrm{b}}$ \\
\hline $\mathrm{N}$ & 4,083 & 288 & 140 & & 42 & 28 & & 87 & 63 & \\
\hline Gender ( $\%$ male) & 49.7 & 51.4 & 58.6 & 0.162 & 52.4 & 57.1 & 0.695 & 72.4 & 57.1 & 0.051 \\
\hline Age (years, mean (S.D.)) & $61.3(4.2)$ & $62.6(4.1)$ & $63.7(3.9)$ & 0.015 & $62.4(3.9)$ & $63.1(4.1)$ & 0.380 & $62.7(4.0)$ & $61.9(3.9)$ & 0.202 \\
\hline Family History of CRC (n (\% yes)) & $235(5.8)$ & $37(12.9)$ & $14(10.0)$ & 0.394 & $4(9.5)$ & $0(0)$ & 0.093 & $9(10.3)$ & $8(12.7)$ & 0.654 \\
\hline BMI $\left(\mathrm{kg} / \mathrm{m}^{2}\right.$, mean (S.D. $\left.)\right)$ & $25.0(3.1)$ & $25.5(3.2)$ & $25.7(3.3)$ & 0.371 & $25.6(2.6)$ & $25.6(3.4)$ & 0.981 & $24.9(2.9)$ & $25.5(2.9)$ & 0.283 \\
\hline \multicolumn{11}{|l|}{ Physical activity $(n,(\%))$} \\
\hline$<30$ & $825(20.4)$ & $56(19.7)$ & $32(23.4)$ & & $6(14.3)$ & $4(14.3)$ & & $17(19.5)$ & $16(25.8)$ & \\
\hline $30-60$ & $1,274(31.5)$ & $92(32.3)$ & $42(30.7)$ & & $11(26.2)$ & $10(35.7)$ & & $26(29.9)$ & $18(29.0)$ & \\
\hline $60-90$ & $850(21.0)$ & $56(19.7)$ & $32(23.4)$ & & $10(23.8)$ & $9(32.1)$ & & $17(19.5)$ & 14 (22.6) & \\
\hline$>90$ & $1091(27.0)$ & $81(28.4)$ & $31(22.6)$ & 0.481 & $15(35.7)$ & $5(17.9)$ & 0.421 & $27(31.0)$ & $14(22.6)$ & 0.625 \\
\hline Energy intake (kJ/day, mean (S.D.)) & $8,072(2,159)$ & $7,982(2,053)$ & $80,734(1,962)$ & 0.661 & $77,078(2,532)$ & $8,009(1,953)$ & 0.597 & $8,404(1,865)$ & $8,375(1,918)$ & 0.925 \\
\hline Fat intake (g/day, mean (S.D.)) & $84.1(27.5)$ & $83.2(26.2)$ & $84.7(26.0)$ & 0.567 & $82.2(35.3)$ & $82.3(22.9)$ & 0.986 & $85.0(23.1)$ & $88.4(27.1)$ & 0.412 \\
\hline $\begin{array}{l}\text { Alcohol consumption (g/day, mean } \\
\text { (S.D.)) }\end{array}$ & $10.4(14.4)$ & $10.9(15.4)$ & $10.9(14.4)$ & 0.965 & $8.8(9.0)$ & $16.4(16.1)$ & 0.106 & $14.1(17.9)$ & $11.4(12.3)$ & 0.648 \\
\hline $\begin{array}{l}\text { Coffee consumption (ml/day, mean } \\
\text { (S.D.)) }\end{array}$ & $538.7(270.0)$ & $537.5(251.0)$ & $541.1(279.2)$ & 0.919 & $503.0(236.7)$ & $517.9(191.6)$ & 0.652 & $575.1(260.0)$ & $584.9(265.3)$ & 0.966 \\
\hline $\begin{array}{l}\text { Calcium intake (mg/day, mean } \\
\text { (S.D.)) }\end{array}$ & $926.5(326.3)$ & $929.6(318.0)$ & $910.5(299.2)$ & 0.553 & $892.6(325.2)$ & $828.5(273.3)$ & 0.393 & $944.4(299.4)$ & $866.3(273.1)$ & 0.104 \\
\hline $\begin{array}{l}\text { Dietary fiber intake (g/day, mean } \\
\text { (S.D.)) }\end{array}$ & $27.0(8.1)$ & $26.8(7.6)$ & $28.1(8.7)$ & 0.093 & $27.0(8.9)$ & $25.7(7.2)$ & 0.523 & $27.9(7.9)$ & $27.7(8.0)$ & 0.891 \\
\hline $\begin{array}{l}\text { Vitamin A intake (mg/day, mean } \\
\text { (S.D.)) }\end{array}$ & $1.0(0.4)$ & $0.9(0.4)$ & $1.0(0.4)$ & 0.820 & $1.2(0.8)$ & $0.9(0.3)$ & 0.185 & $1.0(0.3)$ & $1.0(0.4)$ & 0.880 \\
\hline $\begin{array}{l}\text { Vitamin C intake (mg/day, mean } \\
\text { (S.D.)) }\end{array}$ & $103.7(43.6)$ & $102.3(44.4)$ & $108.1(45.2)$ & 0.208 & $118.3(47.2)$ & $109.0(52.5)$ & 0.441 & $110.6(43.5)$ & $106.5(48.7)$ & 0.586 \\
\hline $\begin{array}{l}\text { Vitamin E intake (mg/day, mean } \\
\text { (S.D.)) }\end{array}$ & $13.4(6.1)$ & $13.3(6.1)$ & $14.8(6.7)$ & 0.024 & $13.5(7.9)$ & $13.8(6.3)$ & 0.852 & $14.1(5.9)$ & $14.3(7.7)$ & 0.859 \\
\hline $\begin{array}{l}\beta \text {-carotene intake ( } \mu \mathrm{g} / \text { day, mean } \\
\text { (S.D.)) }\end{array}$ & $2,961(1,556)$ & $2,878(1,305)$ & $3,022(1,517)$ & 0.681 & $3,399(1,614)$ & $3,062(1,411)$ & 0.415 & $2,948(1,225)$ & $2,935(1,554)$ & 0.536 \\
\hline \multicolumn{11}{|l|}{ Tobacco product $(n,(\%))$} \\
\hline Never smokers & $1,375(33.7)$ & $97(33.7)$ & $50(35.7)$ & 0.678 & $9(21.4)$ & $3(10.7)$ & 0.244 & $20(23.0)$ & $19(30.2)$ & 0.323 \\
\hline Cigarette & $2,076(50.8)$ & $137(47.6)$ & $61(43.6)$ & 0.436 & $24(57.1)$ & $17(60.7)$ & 0.766 & $50(57.5)$ & $29(46.0)$ & 0.166 \\
\hline Cigar & $42(1.0)$ & $2(0.7)$ & $1(0.7)$ & 0.982 & $0(0)$ & $0(0)$ & - & $1(1.2)$ & $0(0)$ & 0.393 \\
\hline Pipe & $8(0.2)$ & $1(0.4)$ & $0(0)$ & 0.485 & $0(0)$ & $0(0)$ & - & $1(1.2)$ & $0(0)$ & 0.393 \\
\hline Cigarette and pipe & $86(2.1)$ & $2(0.7)$ & $4(2.9)$ & 0.074 & $1(2.4)$ & $0(0)$ & 0.411 & $2(2.3)$ & $3(4.8)$ & 0.407 \\
\hline Cigarette and cigar & $268(6.6)$ & $18(6.3)$ & $17(12.1)$ & 0.037 & $3(7.1)$ & $6(21.4)$ & 0.080 & $8(9.2)$ & $8(12.7)$ & 0.493 \\
\hline Cigar and pipe & $22(0.5)$ & $3(1.0)$ & $1(0.7)$ & 0.741 & $0(0)$ & $0(0)$ & - & $0(0)$ & $1(1.6)$ & 0.238 \\
\hline All three products & $206(5.1)$ & $28(9.7)$ & $6(4.3)$ & 0.051 & $5(11.9)$ & $2(7.1)$ & 0.515 & $5(5.8)$ & $3(4.8)$ & 0.791 \\
\hline
\end{tabular}

a Numbers are based on subcohort members and patients without data missing on family history of colorectal cancer, BMI, alcohol or coffee consumption.

${ }^{\mathrm{b}} p$-Value for comparison between patients with wild-type and mutated KRAS gene tumors. 
Table 2

Adjusted $^{\mathrm{a}}$ incidence rate ratios (RR) and corresponding 95\% CI for colorectal cancer, colorectal cancer with wild-type and mutated KRAS gene tumors according to cigarette smoking features

\begin{tabular}{|c|c|c|c|c|c|c|c|c|c|c|}
\hline \multirow[t]{2}{*}{ Cigarette smoking variable } & \multirow{2}{*}{$\begin{array}{l}\text { Personyears } \\
\text { subcohort }^{\mathrm{b}}\end{array}$} & \multicolumn{3}{|c|}{ Colorectal cancer } & \multicolumn{3}{|c|}{ Colorectal cancer-wild-type $K R A S$} & \multicolumn{3}{|c|}{ Colorectal cancer-mutated $K R A S$} \\
\hline & & $N^{\mathrm{c}}$ & $\mathrm{RR}$ & $95 \% \mathrm{CI}$ & $N^{\mathrm{c}}$ & $\mathrm{RR}$ & $95 \% \mathrm{CI}$ & $N^{\mathrm{c}}$ & $\mathrm{RR}$ & $95 \% \mathrm{CI}$ \\
\hline \multicolumn{11}{|l|}{ Smoking status } \\
\hline Never smoker & 9,896 & 198 & 1.00 & Reference & 126 & 1.00 & Reference & 72 & 1.00 & Reference \\
\hline Ex-smoker & 10,502 & 295 & 1.22 & $0.97-1.53$ & 188 & 1.26 & $0.96-1.66$ & 107 & 1.15 & $0.79-1.66$ \\
\hline Current smoker & 8,181 & 144 & 0.81 & $0.62-1.05$ & 95 & 0.86 & $0.62-1.18$ & 49 & 0.72 & $0.47-1.10$ \\
\hline \multicolumn{11}{|l|}{ Frequency (cigarettes/day) } \\
\hline$<10$ & 5,002 & 97 & 0.94 & $0.72-1.24$ & 63 & 0.98 & $0.70-1.36$ & 34 & 0.88 & $0.57-1.36$ \\
\hline $10-20$ & 6,028 & 142 & 1.08 & $0.82-1.42$ & 94 & 1.16 & $0.84-1.61$ & 48 & 0.93 & $0.60-1.46$ \\
\hline$>20$ & 6,605 & 171 & 1.16 & $0.89-1.52$ & 111 & 1.24 & $0.90-1.71$ & 60 & 1.02 & $0.66-1.58$ \\
\hline$p$-Trend & & & 0.23 & & & 0.14 & & & 0.88 & \\
\hline \multicolumn{11}{|l|}{ Duration (years) } \\
\hline$<20$ & 3,288 & 69 & 1.07 & $0.79-1.47$ & 48 & 1.19 & $0.82-1.73$ & 21 & 0.87 & $0.52-1.45$ \\
\hline $20-40$ & 8,636 & 219 & 1.15 & $0.91-1.46$ & 136 & 1.16 & $0.87-1.55$ & 83 & 1.13 & $0.78-1.65$ \\
\hline$>40$ & 6,389 & 144 & 0.86 & $0.65-1.13$ & 94 & 0.93 & $0.67-1.30$ & 50 & 0.73 & $0.47-1.15$ \\
\hline$p$-Trend & & & 0.43 & & & 0.76 & & & 0.33 & \\
\hline \multicolumn{11}{|l|}{ Pack years } \\
\hline$<9$ & 4,905 & 99 & 1.01 & $0.77-1.33$ & 66 & 1.07 & $0.77-1.84$ & 33 & 0.91 & $0.59-1.41$ \\
\hline $10-30$ & 7,336 & 169 & 1.04 & $0.80-1.36$ & 112 & 1.12 & $0.82-1.54$ & 57 & 0.91 & $0.59-1.39$ \\
\hline$>30$ & 5,141 & 138 & 1.12 & $0.84-1.49$ & 87 & 1.16 & $0.82-1.64$ & 51 & 1.03 & $0.64-1.64$ \\
\hline$p$-Trend & & & 0.47 & & & 0.37 & & & 0.95 & \\
\hline \multicolumn{11}{|l|}{ Age at first exposure (years) } \\
\hline$<17$ & 7,170 & 185 & 1.18 & $0.89-1.56$ & 116 & 1.18 & $0.85-1.66$ & 69 & 1.17 & $0.74-1.84$ \\
\hline $17-21$ & 7,310 & 167 & 1.08 & $0.84-1.40$ & 105 & 1.08 & $0.79-1.48$ & 62 & 1.08 & $0.71-1.63$ \\
\hline$>21$ & 3,980 & 78 & 0.90 & $0.67-1.20$ & 54 & 0.99 & $0.70-1.39$ & 24 & 0.75 & $0.46-1.22$ \\
\hline$p$-Trend & & & 0.45 & & & 0.84 & & & 0.27 & \\
\hline \multicolumn{11}{|l|}{ Years since cessation (years) } \\
\hline$<10$ & 11,830 & 252 & 0.96 & $0.76-1.22$ & 165 & 1.02 & $0.77-1.35$ & 87 & 0.86 & $0.59-1.26$ \\
\hline $10-30$ & 5,873 & 168 & 1.24 & $0.96-1.61$ & 104 & 1.24 & $0.91-1.70$ & 64 & 1.23 & $0.82-1.86$ \\
\hline$>30$ & 924 & 17 & 0.78 & $0.45-1.33$ & 13 & 0.97 & $0.52-1.78$ & 4 & 0.47 & $0.17-1.32$ \\
\hline$p$-Trend & & & 0.33 & & & 0.29 & & & 0.78 & \\
\hline \multicolumn{11}{|l|}{ Inhalation } \\
\hline No & 5,354 & 107 & 0.90 & $0.69-1.17$ & 67 & 0.92 & $0.66-1.27$ & 40 & 0.86 & $0.56-1.31$ \\
\hline Yes & 12,874 & 318 & 1.15 & $0.91-1.47$ & 209 & 1.25 & $0.94-1.67$ & 109 & 0.99 & $0.67-1.47$ \\
\hline \multicolumn{11}{|l|}{ Filter usage } \\
\hline Filter-tipped & 5,043 & 103 & 1.04 & $0.79-1.36$ & 66 & 1.05 & $0.76-1.46$ & 37 & 1.01 & $0.66-1.54$ \\
\hline Non-filter-tipped & 8,892 & 230 & 1.07 & $0.82-1.40$ & 148 & 1.12 & $0.82-1.53$ & 82 & 1.00 & $0.65-1.53$ \\
\hline
\end{tabular}

${ }^{\text {a }}$ RRs are adjusted for age (years), sex, family history of colorectal cancer (yes/no), body mass index $\left(\mathrm{kg} / \mathrm{m}^{2}\right)$, alcohol and coffee consumption ( $\mathrm{g} / \mathrm{day}$ ).

${ }^{b}$ Personyears are estimated from the subcohort.

${ }^{c}$ Missing values of smoking characteristics gave rise to diminished personyears and number of colorectal cancer cases for the different smoking variables.

Table 3 presents the multivariate-adjusted RRs and corresponding $95 \%$ confidence intervals for colorectal cancer patients with $\mathrm{G}: \mathrm{C} \rightarrow \mathrm{T}:$ A transversions $(n=72)$ and patients with $\mathrm{G}: \mathrm{C} \rightarrow \mathrm{A}: \mathrm{T}$ transitions $(n=131)$ in KRAS in their tumors. With regard to $\mathrm{G}: \mathrm{C} \rightarrow \mathrm{T}:$ A transversions, smoking frequency was significantly and inversely associated with the risk for tumors with such mutations $(p=0.03)$. None of the other smoking variables were associated with the risk for this type of tumor, but the number of cases in some of the smoking categories is too small to adequately interpret the results. Regarding colorectal cancer with specific $\mathrm{G}: \mathrm{C} \rightarrow \mathrm{A}: \mathrm{T}$ transitions, a J-shaped association was observed with smoking frequency. The incidence rate ratio was significantly decreased for the lowest category of frequency (RR $0.44 ; 95 \%$ CI $0.21-0.94$ ) and was non-significantly increased for the highest category (RR $1.43 ; 95 \%$ CI $0.83-2.45$ ). There were no significant associations between risk for colorectal cancer with specific $\mathrm{G}: \mathrm{C} \rightarrow \mathrm{A}: \mathrm{T}$ transitions and smoking status, duration, pack years, age at first exposure, years since cessation, inhalation or filter usage.

The analyses described above were also conducted for colon, rectosigmoid and rectum cancer separately, and there were no apparent differences in associations with smoking variables between various sites of the colorectal tract, although in some subgroups the numbers of cases were too small to draw definite conclusions. Therefore, the data for the various sites are not shown and discussed any further.

In general, associations with the risk for wild-type $K R A S$ colorectal tumors appeared stronger in men (Table 4) than in the 
Table 3

Adjusted $^{\mathrm{a}}$ incidence rate ratios (RR) and corresponding 95\% CI for colorectal cancer with G:C>T:A transversions and G:C > A:T transitions

\begin{tabular}{|c|c|c|c|c|c|c|c|}
\hline \multirow[t]{2}{*}{ Cigarette smoking variable } & \multirow{2}{*}{$\begin{array}{l}\text { Personyears } \\
\text { subcohort }^{\text {b }}\end{array}$} & \multicolumn{3}{|c|}{ Colorectal cancer with $\mathrm{G}: \mathrm{C}>\mathrm{T}$ :A transversions } & \multicolumn{3}{|c|}{ Colorectal cancer with $\mathrm{G}: \mathrm{C}>\mathrm{A}: \mathrm{T}$ transitions } \\
\hline & & $N^{\mathrm{c}}$ & RR & $95 \% \mathrm{CI}$ & $N$ & RR & $95 \% \mathrm{CI}$ \\
\hline \multicolumn{8}{|l|}{ Smoking status } \\
\hline Never smoker & 9,896 & 25 & 1.00 & Reference & 40 & 1.00 & Reference \\
\hline Ex-smoker & 10,502 & 28 & 0.95 & $0.49-1.85$ & 63 & 1.16 & $0.72-1.86$ \\
\hline Current smoker & 8,181 & 19 & 0.84 & $0.43-1.66$ & 28 & 0.70 & $0.41-1.21$ \\
\hline \multicolumn{8}{|l|}{ Frequency (cigarettes/day) } \\
\hline$<10$ & 5,002 & 19 & 1.35 & $0.72-2.56$ & 9 & 0.44 & $0.21-0.94$ \\
\hline $10-20$ & 6,028 & 12 & 0.59 & $0.27-1.31$ & 29 & 1.11 & $0.62-2.00$ \\
\hline$>20$ & 6,605 & 12 & 0.50 & $0.23-1.10$ & 43 & 1.43 & $0.83-2.45$ \\
\hline$p$-Trend & & & 0.03 & & & 0.08 & \\
\hline \multicolumn{8}{|l|}{ Duration (years) } \\
\hline$<20$ & 3,288 & 8 & 0.98 & $0.44-2.19$ & 12 & 0.89 & $0.45-1.76$ \\
\hline $20-40$ & 8,636 & 20 & 0.81 & $0.40-1.63$ & 51 & 1.23 & $0.76-1.96$ \\
\hline$>40$ & 6,389 & 17 & 0.71 & $0.34-1.50$ & 28 & 0.70 & $0.39-1.26$ \\
\hline$p$-Trend & & & 0.35 & & & 0.40 & \\
\hline \multicolumn{8}{|l|}{ Pack years } \\
\hline$<9$ & 4,905 & 14 & 1.09 & $0.56-2.15$ & 13 & 0.68 & $0.35-1.29$ \\
\hline $10-30$ & 7,336 & 15 & 0.63 & $0.29-1.36$ & 34 & 1.04 & $0.60-1.81$ \\
\hline$>30$ & 5,141 & 13 & 0.68 & $0.31-1.50$ & 34 & 1.29 & $0.71-2.32$ \\
\hline$p$-Trend & & & 0.22 & & & 0.32 & \\
\hline \multicolumn{8}{|l|}{ Age at first exposure (years) } \\
\hline$<17$ & 7,170 & 24 & 1.40 & $0.62-3.20$ & 37 & 1.03 & $0.58-1.82$ \\
\hline $17-21$ & 7,310 & 16 & 0.93 & $0.44-1.99$ & 39 & 1.14 & $0.68-1.93$ \\
\hline$>21$ & 3,980 & 6 & 0.56 & $0.22-1.40$ & 15 & 0.80 & $0.43-1.48$ \\
\hline$p$-Trend & & & 0.13 & & & 0.71 & \\
\hline \multicolumn{8}{|l|}{ Years since cessation (years) } \\
\hline$<10$ & 1,1830 & 28 & 0.82 & $0.43-1.58$ & 50 & 0.85 & $0.53-1.38$ \\
\hline $10-30$ & 5,873 & 17 & 1.02 & $0.48-2.13$ & 38 & 1.28 & $0.75-2.18$ \\
\hline$>30$ & 924 & 1 & 0.36 & $0.05-2.66$ & 3 & 0.63 & $0.19-2.06$ \\
\hline$p$-Trend & & & 0.65 & & & 0.58 & \\
\hline \multicolumn{8}{|l|}{ Inhalation } \\
\hline No & 5,354 & 16 & 1.01 & $0.51-1.99$ & 20 & 0.76 & $0.43-1.32$ \\
\hline Yes & 12,874 & 29 & 0.77 & $0.39-1.52$ & 66 & 1.05 & $0.63-1.75$ \\
\hline \multicolumn{8}{|l|}{ Filter usage } \\
\hline Filter-tipped & 5,043 & 16 & 1.19 & $0.62-2.29$ & 19 & 0.92 & $0.52-1.64$ \\
\hline Non-filter-tipped & 8,892 & 20 & 0.53 & $0.26-1.07$ & 50 & 1.21 & $0.70-2.10$ \\
\hline
\end{tabular}

${ }^{\text {a }}$ RRs are adjusted for age (years), sex, family history of colorectal cancer (yes/no), body mass index ( $\mathrm{kg} / \mathrm{m}^{2}$ ), alcohol and coffee consumption ( $\mathrm{g} / \mathrm{day}$ ).

b Personyears are estimated from the subcohort.

c Missing values of smoking characteristics gave rise to diminished personyears and number of colorectal cancer cases for the different smoking variables.

total group as presented in Table 2. Associations with smoking variables were absent for $K R A S$-mutated colorectal tumors in men and for both end points in women (Table 4). In men, the risk of $K R A S$ wild-type colorectal tumors was increased significantly in ex-smokers compared with never smokers (RR $1.79,95 \%$ CI 1.00-3.20), whereas for current smokers no significantly increased risk was observed compared with never smokers (RR 1.23, 95\% CI 0.66-2.31). There was a significant trend for increased $K R A S$ wild-type colorectal cancer risk with increasing frequency of cigarette smoking in men $(p$ trend=0.02). For men smoking more than 20 cigarettes/day, compared with never smokers, the RR was 1.91 , which was statistically significant (95\% CI 1.03-3.52). For men inhaling cigarette smoke versus never smokers, the RR for KRAS wild-type tumors was also elevated, although not statistically significantly (RR 1.69, 95\% CI 0.94-3.04, not shown in the table).

For ex-smokers, both frequency and duration of smoking were associated with an increased risk for wild-type KRAS colorectal tumors, when compared with never smokers, although this was not statistically significant (Table 5). Smoking more than 20 cigarettes/day versus never smoking was associated with a 35 percent increased risk of $K R A S$ wild-type tumors $(95 \% \mathrm{CI}$ $0.92-1.99$ and $p$-trend $=0.09)$. Smoking cigarettes for more than 40 years was associated with a $44 \%$ increased risk of KRAS wild-type tumors (95\% CI 0.89-2.33, $p$-trend=0.07). Although the risk for mutated KRAS tumors was also elevated, although not statistically significantly, in ex-smokers who smoked more than 20 cigarettes/day versus never smokers, there was no clear trend (RR 1.40, 95\% CI 0.84-2.33, $p$-trend $=0.22$ ). In current 
Table 4

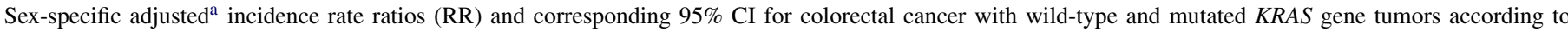
cigarette smoking status, frequency and duration

\begin{tabular}{|c|c|c|c|c|c|c|c|}
\hline \multirow[t]{2}{*}{ Cigarette smoking variable } & \multirow{2}{*}{$\begin{array}{l}\text { Personyears } \\
\text { subcohort }^{\mathrm{b}}\end{array}$} & \multicolumn{3}{|c|}{ Colorectal cancer-wild-type $K R A S$} & \multicolumn{3}{|c|}{ Colorectal cancer-mutated $K R A S$} \\
\hline & & $N^{\mathrm{c}}$ & RR & $95 \% \mathrm{CI}$ & $N^{\mathrm{c}}$ & RR & $95 \% \mathrm{CI}$ \\
\hline & & \multicolumn{3}{|c|}{ Men } & & & \\
\hline \multicolumn{8}{|l|}{ Smoking status } \\
\hline Never smoker & 1366 & 14 & 1.00 & Reference & 11 & 1.00 & Reference \\
\hline Ex-smoker & 7444 & 147 & 1.79 & $1.00-3.20$ & 85 & 1.20 & $0.61-2.33$ \\
\hline Current smoker & 5036 & 64 & 1.23 & $0.66-2.31$ & 35 & 0.78 & $0.39-1.58$ \\
\hline \multicolumn{8}{|l|}{ Frequency (cigarettes/day) } \\
\hline$<10$ & 2294 & 34 & 1.33 & $0.69-2.57$ & 21 & 1.02 & $0.48-2.19$ \\
\hline $10-20$ & 4236 & 66 & 1.48 & $0.80-2.76$ & 35 & 0.93 & $0.46-1.90$ \\
\hline$>20$ & 5148 & 97 & 1.91 & $1.03-3.52$ & 53 & 1.17 & $0.58-2.36$ \\
\hline$p$-Trend & & & 0.02 & & & 0.57 & \\
\hline \multicolumn{8}{|l|}{ Duration (years) } \\
\hline$<20$ & 1758 & 29 & 1.77 & $0.90-3.48$ & 15 & 1.15 & $0.52-2.58$ \\
\hline $20-40$ & 5545 & 100 & 1.72 & $0.95-3.12$ & 65 & 1.31 & $0.67-2.58$ \\
\hline$>40$ & 4971 & 78 & 1.39 & $0.74-2.59$ & 40 & 0.78 & $0.38-1.59$ \\
\hline$p$-Trend & & & 0.82 & & & 0.20 & \\
\hline \multicolumn{8}{|c|}{ Women } \\
\hline \multicolumn{8}{|l|}{ Smoking status } \\
\hline Never smoker & 8530 & 112 & 1.00 & Reference & 61 & 1.00 & Reference \\
\hline Ex-smoker & 3058 & 41 & 1.09 & $0.74-1.62$ & 22 & 1.10 & $0.67-1.82$ \\
\hline Current smoker & 3146 & 31 & 0.75 & $0.48-1.17$ & 14 & 0.67 & $0.35-1.28$ \\
\hline \multicolumn{8}{|l|}{ Frequency (cigarettes/day) } \\
\hline$<10$ & 2708 & 29 & 0.89 & $0.57-1.41$ & 13 & 0.75 & $0.40-1.40$ \\
\hline $10-20$ & 1791 & 28 & 1.26 & $0.80-1.97$ & 13 & 1.18 & $0.63-2.19$ \\
\hline$>20$ & 1457 & 14 & 0.69 & $0.38-1.25$ & 7 & 0.68 & $0.28-1.64$ \\
\hline$p$-Trend & & & 0.60 & & & 0.57 & \\
\hline \multicolumn{8}{|l|}{ Duration (years) } \\
\hline$<20$ & 1530 & 19 & 1.04 & $0.61-1.76$ & 6 & 0.63 & $0.26-1.49$ \\
\hline $20-40$ & 3091 & 36 & 0.96 & $0.63-1.46$ & 18 & 0.96 & $0.55-1.68$ \\
\hline$>40$ & 1419 & 16 & 0.79 & $0.46-1.36$ & 10 & 0.94 & $0.46-1.91$ \\
\hline$p$-Trend & & & 0.48 & & & 0.79 & \\
\hline
\end{tabular}

${ }^{a}$ RRs are adjusted for age (years), family history of colorectal cancer (yes/no), body mass index ( $\mathrm{kg} / \mathrm{m}^{2}$ ), alcohol and coffee consumption (g/day).

b Personyears are estimated from the subcohort.

c Missing values of smoking characteristics gave rise to diminished personyears and number of colorectal cancer cases for the different smoking variables.

smokers, there was no increased risk for wild-type or mutated $K R A S$ tumors according to frequency or duration of smoking. For mutated KRAS tumors, a slight protective effect was even observed in current smokers with frequency $(p$-trend $=0.06$ ) and duration ( $p$-trend $=0.05$ ) of smoking. However, we have to acknowledge that the number of cases were low in the current smoking group of cases with mutated KRAS tumors. Specifically, since people generally started smoking at a very early age, the number of current smokers who smoked less than 10 years was rare.

\section{Discussion}

In the Netherlands Cohort Study on diet and cancer (NLCS) we observed that current smoking was not associated with the risk for overall colorectal cancer, colorectal cancer with wildtype KRAS tumors or colorectal cancer with mutated KRAS tumors. Former smoking, frequency of cigarette smoking and inhalation were non-significantly associated with increased risk of colorectal cancer overall and with colorectal cancer with a wild-type KRAS gene compared to never smoking, whereas associations were not apparent with respect to the risk for colorectal cancer with mutated KRAS tumors. The associations with wildtype KRAS tumors appeared strongest for men and ex-smokers and were not apparent for women and current smokers. Furthermore, no clear associations were observed between smoking and colorectal cancer with specific $\mathrm{G}: \mathrm{C} \rightarrow \mathrm{T}: \mathrm{A}$ transversions or $\mathrm{G}: \mathrm{C} \rightarrow \mathrm{A}: \mathrm{T}$ transitions in KRAS. In contrast to what we expected, smoking was not associated with the risk for colorectal cancer with KRAS oncogene mutations.

Few studies have looked at cigarette smoking and colorectal cancer while assessing KRAS mutation status. A summary of the studies is given in Table 6. Regarding risk for KRASmutated tumors, none of the four studies showed a significant association between cigarette smoking and risk for colon carcinomas or colorectal adenomas with mutated KRAS [19-22]. This is in line with our observations that none of the investigated cigarette-smoking variables are associated with the risk for col- 
Table 5

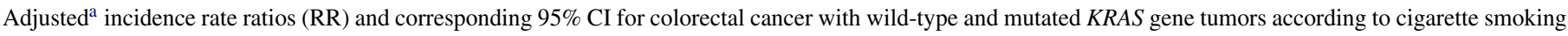
frequency and duration for ex-smokers and current smokers separately

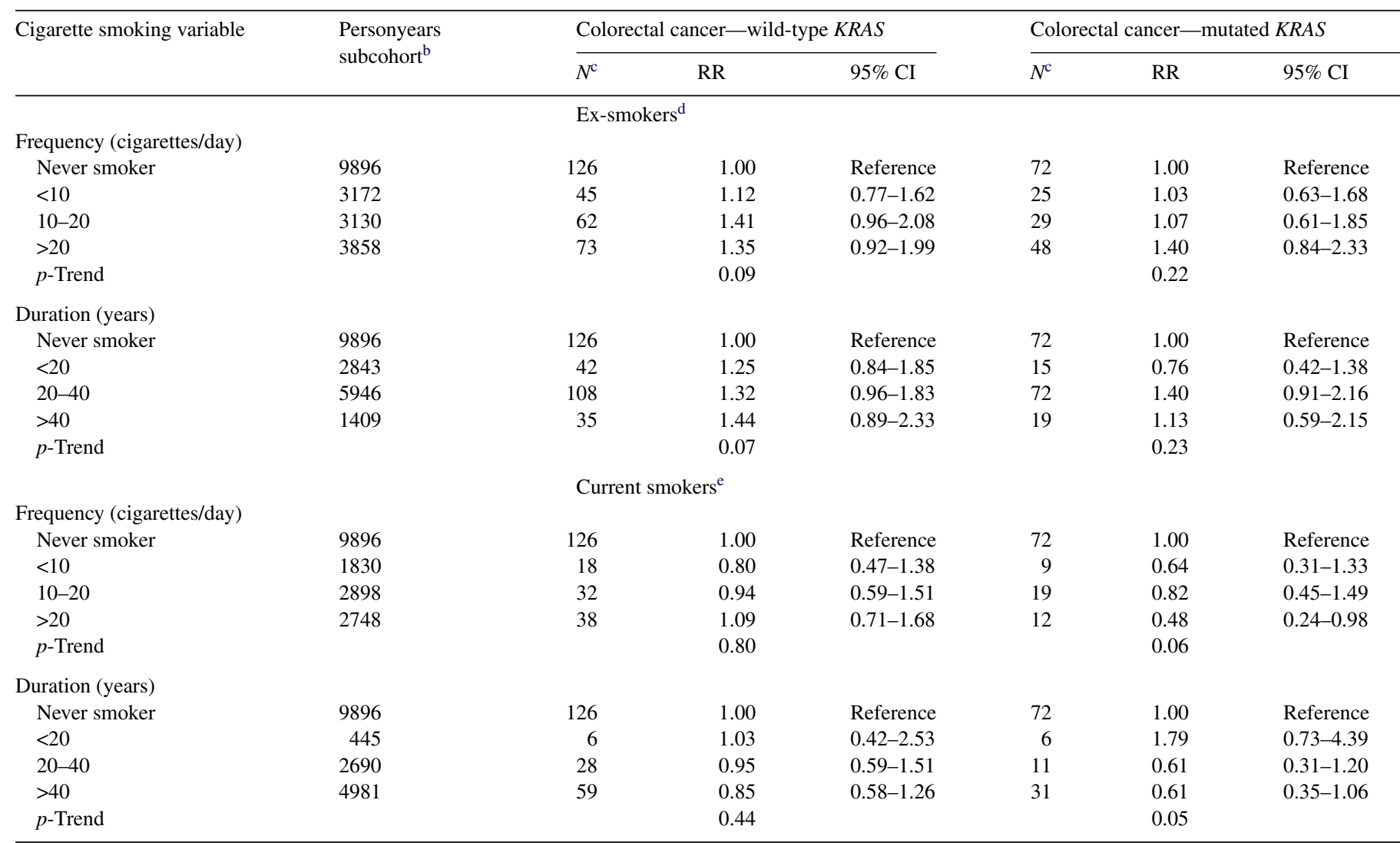

a RRs are adjusted for age (years), sex, family history of colorectal cancer (yes/no), body mass index (kg/m²), alcohol and coffee consumption (g/day).

b Personyears are estimated from the subcohort.

c Missing values of smoking characteristics gave rise to diminished personyears and number of colorectal cancer cases for the different smoking variables.

${ }^{\mathrm{d}}$ In analyses for ex-smokers all current smokers were deleted from the analyses, and never smokers form the reference category.

e In analyses for current smokers all ex-smokers were deleted from the analyses, and never smokers form the reference category.

orectal carcinomas with mutated KRAS. However, in contrast to our study, the reported risks in the other studies in Table 6 are slightly elevated, although they never reach statistical significance.

We expected smoking variables to be associated with tumors harboring specific point mutations in KRAS since genotoxic compounds of cigarette smoke have been shown to induce specific $\mathrm{G}: \mathrm{C} \rightarrow \mathrm{A}: \mathrm{T}$ and $\mathrm{G}: \mathrm{C} \rightarrow \mathrm{T}:$ A mutations in $R A S$ oncogenes in rodents. The only finding from our study that fits this hypothesis is the non-significantly elevated risk for tumors with $\mathrm{G}: \mathrm{C}>\mathrm{A}: \mathrm{T}$ transitions with smoking more than 20 cigarettes a day versus never smoking. However, the overall association between smoking frequency and tumors with $\mathrm{G}: \mathrm{C}>\mathrm{A}$ :T transitions had a U-shape, and a significant inverse trend with smoking frequency was observed for tumors with $\mathrm{G}: \mathrm{C} \rightarrow \mathrm{T}$ :A transversions. Finally, we expected an association with long-term smoking, thus smoking duration, but this was not observed. Overall this leaves us to conclude that there is no clear association between smoking variables and tumors with specific point mutations in KRAS. This is in line with the findings from Slattery's large case-control study [19] in which no associations between smoking and risks for $\mathrm{G}: \mathrm{C} \rightarrow \mathrm{A}: \mathrm{T}$ transitions or $\mathrm{G}: \mathrm{C} \rightarrow \mathrm{T}: \mathrm{A}$ transversions were observed when smoking $\geq 20$ cigarettes/day was compared with not smoking (transitions OR 0.8, 95\% CI 0.6-1.2, transversions OR 0.9, 95\% CI 0.7-1.3). Diergaarde et al. [20] observed a positive association, although not significant, between cigarette smoking and tumors with $\mathrm{G}: \mathrm{C} \rightarrow \mathrm{T}: \mathrm{A}$ transversion mutations in KRAS (KRAS transversions vs. controls; OR 2.2, 95\% CI 0.7-6.3). This association was not found between cigarette smoking and $\mathrm{G}: \mathrm{C} \rightarrow \mathrm{A}: \mathrm{T}$ transitions in KRAS (KRAS transitions vs. controls; OR 1.0, 95\% CI 0.4-2.5) [20].

Surprisingly, the most consistent observation seems to be an association between cigarette smoking and wild-type $K R A S$ colorectal tumors [19,21]. Two out of the four other studies summarized in Table 6 also suggest that associations between cigarette smoking and colorectal tumors are more pronounced with wild-type $K R A S$ tumors. In line with our results, Slattery et al.[19] observed an increased risk for having a wild-type $K R A S$ colon tumor when smoking $\geq 20$ cigarettes/day (wild-type $K R A S$ vs. controls; OR 1.3, 95\% CI 1.1-1.6), compared with never smoking. Wark et al. [21] reported that both current and former smokers, compared with never smokers, are at increased risk for wild-type $K R A S$ colorectal adenomas, but not mutated $K R A S$ adenomas, in their case-control study (wild-type KRAS 
Table 6

Summary of studies of cigarette smoking and colorectal cancer

\begin{tabular}{|c|c|c|c|c|c|}
\hline Author & Reference & Design & \# Cases/controls & Outcome & OR $(95 \% \mathrm{CI})$ \\
\hline Slattery et al. & [19] & Case-control study & $\begin{array}{l}\text { Mutated KRAS: } 453 \\
\text { Wild-type KRAS: } 968 \\
\text { Controls: } 2404\end{array}$ & Colon carcinomas & $\begin{array}{l}\text { >20 cigarettes/day vs. none cigarettes/day: } \\
\text { Mutated } K R A S \text { vs. controls: } 1.2(0.9-1.5) \\
\text { Wild-type } K R A S \text { vs. controls: } 1.3(1.1-1.6) \\
K R A S \text { transversion vs. controls: } 0.9(0.7-1.3) \\
K R A S \text { transitions vs. controls: } 0.8(0.6-1.2)\end{array}$ \\
\hline Diergaarde et al. & [20] & Case-control study & $\begin{array}{l}\text { Mutated KRAS: } 64 \\
\text { Wild-type KRAS: } 112 \\
\text { Controls: } 249 \\
\text { KRAS transversions: } 31 \\
\text { KRAS transitions: } 33\end{array}$ & Colon carcinomas & $\begin{array}{l}\text { Ever smokers vs. never smokers: } \\
\text { Mutated KRAS vs. controls: } 1.4(0.7-2.8) \\
\text { Wild-type } K R A S \text { vs. controls: } 0.8(0.5-1.4) \\
K R A S \text { transversion vs. controls: } 2.2(0.7-6.3) \\
K R A S \text { transitions vs. controls: } 1.0(0.4-2.5)\end{array}$ \\
\hline Wark et al. & [21] & Case-control study & $\begin{array}{l}\text { Mutated KRAS: } 81 \\
\text { Wild-type KRAS: } 453 \\
\text { Controls: } 709\end{array}$ & Colorectal adenomas & $\begin{array}{l}\text { Former smokers vs. never smokers: } \\
\text { Mutated } K R A S \text { vs. controls: } 1.20(0.70-2.08) \\
\text { Wild-type } K R A S \text { vs. controls: } 1.45(1.08-1.96) \\
\text { Current smokers vs. never smokers: } \\
\text { Mutated } K R A S \text { vs. controls: } 1.27(0.66-2.42) \\
\text { Wild-type } K R A S \text { vs. controls: } 2.04(1.47-2.83)\end{array}$ \\
\hline Martinez et al. & [22] & Cross-sectional study & $\begin{array}{l}\text { Mutated KRAS: } 120 \\
\text { Wild-type } K R A S: 558\end{array}$ & Colorectal adenomas & $\begin{array}{l}\text { Past smokers vs. never smokers: } \\
\text { Mutated } K R A S \text { vs. wild-type } K R A S: 1.07(0.67-1.70) \\
\text { Current smokers vs. never smokers: } \\
\text { Mutated } K R A S \text { vs. wild-type } K R A S: 1.17(0.61-2.25)\end{array}$ \\
\hline Present study & & Cohort study & $\begin{array}{l}\text { Mutated KRAS: } 81 \\
\text { Wild-type } K R A S: 453 \\
\text { Subcohort: } 4083\end{array}$ & Colorectal cancer & $\begin{array}{l}\text { Former smokers vs. never smokers: } \\
\text { Mutated } K R A S \text { vs. never smokers: } 1.15(0.79-1.66) \\
\text { Wild type } K R A S \text { vs. never smokers: } 1.26(0.96-1.66) \\
\text { Current smokers vs. never smokers: } \\
\text { Mutated } K R A S \text { vs. never smokers: } 0.72(0.47-1.10) \\
\text { Wild type } K R A S \text { vs. never smokers: } 0.86(0.62-1.18)\end{array}$ \\
\hline
\end{tabular}

vs. controls; OR 2.04, 95\% CI $1.47-2.83$ and OR $1.45,95 \%$ CI 1.08-1.96, for current and former smokers, respectively, compared with never smokers). In another case-control study on cigarette smoking and sporadic colon carcinomas by Diergaarde et al. [20], ever-smokers were not at increased risk for having tumors with wild-type $K R A S$ (wild-type $K R A S$ vs. controls; OR $0.8,95 \%$ CI 0.5-1.4).

Our finding that the association of smoking variables with wild-type KRAS tumors was strongest for men and not apparent for women was also observed by Slattery et al. [19]. None of the other studies reported sex-specific associations [20-22]. In the present study, women smoked considerably less than men, leaving relatively small numbers of female cases in different subgroups of smoking variables (see Table 4). This may have influenced the results, but we should also note that there was no significant effect modification by gender in this study. However, it is worthwhile to further explore the strength of the association between smoking and KRAS wild-type colorectal cancer in women in future studies.

Our finding that associations between smoking frequency and duration and wild-type $K R A S$ tumors was present in ex-smokers but not current smokers, all compared with never smokers, is puzzling. Others have not reported such differences [19-22]. In our population, most people who ever smoked were ex-smokers. Many of these ex-smokers had smoked at a high frequency and for a long time. Therefore, their lifetime exposure to smoking was still considerable and may have contributed to the increased cancer risk. The lack of association among the current smokers may reflect that this is a group of subjects that did not quit smoking because of smoking related ill-health and may therefore be less sensitive to the effects of smoking on colorectal cancer than the ex-smokers. However, it should be noted that the associations of the ex-smoking group were not statistically significant and that further research is warranted to tease out potential differential effects of ex- and current smokers on the risk for colorectal cancer, especially wild-type $K R A S$ tumors.

Many years are needed to develop colorectal cancer after initiation. In this period, carcinogens from cigarette smoke cause irreversible genetic damage in the colorectal mucosa. Giovannucci et al. $[23,24]$ suggested that the long lag time between exposure to cigarette smoke and occurrence of colorectal cancer is a possible explanation for smoking being a risk for colorectal adenomas but not for colorectal cancer. In the present study, $84 \%$ of the smokers had smoked for 20 years or more, $33 \%$ had smoked for 40 years or more and $43 \%$ started before the age of 19. These figures are high enough to assume that smoking could have caused colorectal cancer within the timeframe of this cohort study.

Our results indicate that smoking is not associated with the risk for colorectal cancer with KRAS oncogene mutations. However, smoking may be an early event in the development of colorectal cancers that arise through other underlying genetic pathways, such as mutations in the adenomatous polyposis coli (APC) tumor suppressor gene, P53 over-expression or absence 
of hMLH1 expression [20,25-27]. Recently published results from the large case-control study discussed previously [19] suggest that smoking is related to $\mathrm{CpG}$ island methylator phenotype (CIMP) and V600E BRAF mutations in colon cancer, rather than with microsatellite-unstable cancer [28]. This could explain our results with regard to $K R A S$ wild-type tumors, since $K R A S$ mutations are rare in tumors with CIMP and/or BRAF mutations [29].

In contrast to case-control studies, the smoking habits of all subjects in this study were reported before the disease was diagnosed. Information bias, i.e. changes in smoking habits or change in report of smoking habits is therefore almost completely avoided in a prospective cohort study like this one. A change in smoking habits of subjects with pre-clinical colorectal cancer at the time of completing the baseline questionnaire remains possible. The completeness of follow-up together with the prospective nature of a cohort study reduced the potential for selection bias to a minimum. Underreporting of smoking habits because of social desirability remains possible. This could lead to non-differential misclassification of smoking habits. In this study, smoking characteristics are based on active smoking habits. Unfortunately, the effect of passive smoking is therefore not estimated. This may have attenuated the associations observed.

In conclusion, this study indicates that smoking is not associated with the risk for colorectal cancer with specific mutations in the KRAS gene. The study suggests that smoking may be associated with the risk for a specific molecular subgroup of colorectal cancer characterized by wild-type KRAS tumors. For an ex-smoker, smoking frequency and inhalation seemed to be associated with an increased risk for colorectal cancer with wildtype KRAS gene tumors, especially in men. Future studies should tease out whether there are other molecular characteristics of the $K R A S$ wild-type tumors that may better explain the association with cigarette smoking.

\section{Acknowledgements}

We thank Dr. M. Brink for the collection of tissue samples; Dr. Brink and G. Roemen for molecular analyses; Dr. L. Schouten, S. van de Crommert, H. Brants, J. Nelissen, C. de Zwart, M. Moll, W. van Dijk, M. Jansen and A. Pisters for data management; H. van Montfort, T. van Moergastel, L. van den Bosch and R. Schmeitz for programming assistance. We would like to thank Dr. A. Volovics and Dr. A. Kester for statistical advice. Finally, we would like to thank J. Nelissen for entering the results in the tables.

\section{References}

[1] IARC Monographs on the Evaluation of Carcinogenic Risks to Humans (Vol. 83), Tobacco smoke and involuntary smoking, WHO-International Agency for Research on Cancer, Lyon, 2004.

[2] A.J. Sasco, M.B. Secretan, K. Straif, Tobacco smoking and cancer: a brief review of recent epidemiological evidence, Lung Cancer 45 (Suppl. 2) (2004) S3-S9.

[3] E. Giovannucci, An updated review of the epidemiological evidence that cigarette smoking increases risk of colorectal cancer, Cancer Epidemiol. Biomarkers Prev. 10 (2001) 725-731.
[4] B.T. Ji, J.L. Weissfeld, W.H. Chow, W.Y. Huang, R.E. Schoen, R.B. Hayes, Tobacco smoking and colorectal hyperplastic and adenomatous polyps, Cancer Epidemiol. Biomarkers Prev. 15 (2006) 897-901.

[5] E.R. Fearon, B. Vogelstein, A genetic model for colorectal tumorigenesis, Cell 61 (1990) 759-767.

[6] K.W. Kinzler, B. Vogelstein, Lessons from hereditary colorectal cancer, Cell 87 (1996) 159-170

[7] J.L. Bos, E.R. Fearon, S.R. Hamilton, M. Verlaan-de Vries, J.H. van Boom, A.J. van der Eb, B. Vogelstein, Prevalence of ras gene mutations in human colorectal cancers, Nature 327 (1987) 293-297.

[8] B. Vogelstein, E.R. Fearon, S.R. Hamilton, S.E. Kern, A.C. Preisinger, M. Leppert, Y. Nakamura, R. White, A.M. Smits, J.L. Bos, Genetic alterations during colorectal-tumor development, N Engl. J. Med. 319 (1988) 525-532.

[9] J. Breivik, G.I. Meling, A. Spurkland, T.O. Rognum, G. Gaudernack, Kras mutation in colorectal cancer: relations to patient age, sex and tumour location, Br. J. Cancer 69 (1994) 367-371.

[10] M. Brink, A.F. de Goeij, M.P. Weijenberg, G.M. Roemen, M.H. Lentjes, M.M. Pachen, K.M. Smits, A.P. de Bruine, R.A. Goldbohm, P.A. van den Brandt, K-ras oncogene mutations in sporadic colorectal cancer in The Netherlands Cohort Study, Carcinogenesis 24 (2003) 703-710.

[11] C.C. Harris, Chemical and physical carcinogenesis: advances and perspectives for the 1990s, Cancer Res. 51 (1991) 5023s-5044s.

[12] P.A. van den Brandt, R.A. Goldbohm, P. van 't Veer, A. Volovics, R.J. Hermus, F. Sturmans, A large-scale prospective cohort study on diet and cancer in The Netherlands, J. Clin. Epidemiol. 43 (1990) 285295

[13] P.A. Van den Brandt, L.J. Schouten, R.A. Goldbohm, E. Dorant, P.M. Hunen, Development of a record linkage protocol for use in the Dutch cancer registry for epidemiological research, Int. J. Epidemiol. 19 (1990) 553-558.

[14] W.E. Barlow, L. Ichikawa, D. Rosner, S. Izumi, Analysis of case-cohort designs, J. Clin. Epidemiol. 52 (1999) 1165-1172.

[15] A. Volovics, P.A. Van Den Brandt, Methods for the analyses of case-cohort studies, Biom. J. 39 (1997) 159-214.

[16] R.A. Goldbohm, P.A. van den Brandt, H.A. Brants, P. van't Veer, M. Al, F. Sturmans, R.J. Hermus, Validation of a dietary questionnaire used in a large-scale prospective cohort study on diet and cancer, Eur. J. Clin. Nutr. 48 (1994) 253-265.

[17] D.Y. Lin, L.J. Wei, The robust inference for the Cox Proportional Hazards Model, JASA 84 (1989) 1074-1078.

[18] D. Schoenfeld, Partial residuals for the proportional hazards regression models, Biometrika 69 (1982) 239-241.

[19] M.L. Slattery, K. Anderson, K. Curtin, K. Ma, D. Schaffer, S. Edwards, W. Samowitz, Lifestyle factors and Ki-ras mutations in colon cancer tumors, Mutat. Res. 483 (2001) 73-81.

[20] B. Diergaarde, A. Vrieling, A.A. van Kraats, G.N. van Muijen, F.J. Kok, E. Kampman, Cigarette smoking and genetic alterations in sporadic colon carcinomas, Carcinogenesis 24 (2003) 565-571.

[21] P.A. Wark, W. Van der Kuil, J. Ploemacher, G.N. Van Muijen, C.J. Mulder, M.P. Weijenberg, F.J. Kok, E. Kampman, Diet, lifestyle and risk of K-ras mutation-positive and -negative colorectal adenomas, Int. J. Cancer 119 (2006) 398-405

[22] M.E. Martinez, T. Maltzman, J.R. Marshall, J. Einspahr, M.E. Reid, R. Sampliner, D.J. Ahnen, S.R. Hamilton, D.S. Alberts, Risk factors for Kiras protooncogene mutation in sporadic colorectal adenomas, Cancer Res. 59 (1999) 5181-5185.

[23] E. Giovannucci, E.B. Rimm, M.J. Stampfer, G.A. Colditz, A. Ascherio, J. Kearney, W.C. Willett, A prospective study of cigarette smoking and risk of colorectal adenoma and colorectal cancer in U.S. men, J. Natl. Cancer Inst. 86 (1994) 183-191.

[24] E. Giovannucci, G.A. Colditz, M.J. Stampfer, D. Hunter, B.A. Rosner, W.C. Willett, F.E. Speizer, A prospective study of cigarette smoking and risk of colorectal adenoma and colorectal cancer in U.S. women, J. Natl. Cancer Inst. 86 (1994) 192-199.

[25] M. Luchtenborg, M.P. Weijenberg, E. Kampman, G.N. van Muijen, G.M. Roemen, M.P. Zeegers, R.A. Goldbohm, P. van 't Veer, A.F. de Goeij, P.A. van den Brandt, Cigarette smoking and colorectal cancer: APC muta- 
tions, hMLH1 expression, and GSTM1 and GSTT1 polymorphisms, Am. J. Epidemiol. 161 (2005) 806-815.

[26] P. Yang, J.M. Cunningham, K.C. Halling, T.G. Lesnick, L.J. Burgart, E.M. Wiegert, E.R. Christensen, N.M. Lindor, J.A. Katzmann, S.N. Thibodeau, Higher risk of mismatch repair-deficient colorectal cancer in alpha(1)antitrypsin deficiency carriers and cigarette smokers, Mol. Genet. Metab. 71 (2000) 639-645.

[27] A.H. Wu, D. Shibata, M.C. Yu, M.Y. Lai, R.K. Ross, Dietary heterocyclic amines and microsatellite instability in colon adenocarcinomas, Carcinogenesis 22 (2001) 1681-1684.
[28] W.S. Samowitz, H. Albertsen, C. Sweeney, J. Herrick, B.J. Caan, K.E. Anderson, R.K. Wolff, M.L. Slattery, Association of smoking, CpG island methylator phenotype, and V600E BRAF mutations in colon cancer, J. Natl. Cancer Inst. 98 (2006) 1731-1738.

[29] H. Tanaka, G. Deng, K. Matsuzaki, S. Kakar, G.E. Kim, S. Miura, M.H. Sleisenger, Y.S. Kim, BRAF mutation, $\mathrm{CpG}$ island methylator phenotype and microsatellite instability occur more frequently and concordantly in mucinous than non-mucinous colorectal cancer, Int. J. Cancer 118 (2006) 2765-2771. 